\title{
Business boom continues
}

$\mathrm{R}$ usiness is still booming in the solar industry despite the current economic climate, with many companies announcing expansions in manufacturing capacity, new contracts and installations of new solar power plants.

Suniva, a US manufacturer of highefficiency monocrystalline silicon solar cells and modules, has expanded its manufacturing capacity from $96 \mathrm{MW}$ to $170 \mathrm{MW}$ by adding a third cell line at its metro-Atlanta plant. The new manufacturing line is now in production and will help the company meet the continually increasing worldwide demand for its product.

Chinese company Yingli Green Energy has expanded its manufacturing capacity by $400 \mathrm{MW}$ with the addition of two new lines for fabricating monocrystalline silicon-based products. These include a $300 \mathrm{MW}$

production capacity at the company's Baoding headquarters and a $100 \mathrm{MW}$ production capacity in Haikou, Hainan province. This expansion will bring the company's total capacity to $1 \mathrm{GW}$.

In the US, Universal Solar Technology, a developer of solar-grade ingot, wafers and high-efficiency solar photovoltaic modules, has signed a sales contract for US\$32.6 million with CEZ Group, part of the largest electricity producer in the Czech Republic. The contract calls for the delivery of $20 \mathrm{MW}$ of monocrystaline solar modules to be delivered by the end of 2010 .

The US Department of Energy (DOE) has been busy funding a variety of solar installations and research projects. The DOE has offered a conditional commitment for a
US $\$ 1.45$ billion loan guarantee to Abengoa Solar that will support the construction and start-up of Solana, a $250 \mathrm{MW}$ concentrating solar power plant in Arizona. The DOE has also offered Abound Solar, a manufacturer of cadmium telluride thin-film photovoltaic solar modules, a conditional commitment for a US\$400 million, seven-year loan guarantee to expand its solar module manufacturing capabilities. Ascent Solar Technology has won a US\$3.8 million contract from the Defense Advanced Research Projects Agency for the development of a flexible high-performance tandem-junction photovoltaic array. The goal of the programme is to demonstrate low-cost, lightweight photovoltaics that can withstand battle conditions and environmental extremes while delivering a power-conversion efficiency of $20 \%$ or greater.

\section{Solar planes set records}

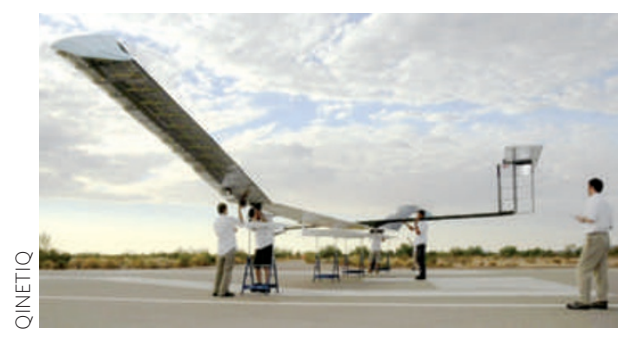

Two new records have been set in the world of solar-powered aviation. Zephyr, an unmanned aerial vehicle developed by UK firm QinetiQ, has flown continuously for more than a week; and the HB-SIA, a solarpowered plane developed by Swiss company Solar Impulse, has successfully completed the first ever night flight for a solar plane.

Zephyr weighs only $50 \mathrm{~kg}$ and has a wingspan of $22.5 \mathrm{~m}$. It is launched by hand and is powered by amorphous silicon photovoltaic cells situated on its wings. Using a solar charger developed by QinetiQ, the cells charge up lithium-sulphur batteries to allow night-time flying. Potential applications for Zephyr include earth observation and communications relay.

Solar Impulse's HB-SIA, on the other hand, has an on-board pilot, the wingspan of an Airbus 340 (64 m) and the weight of an average-size family car. Its wings are covered by 11,628 monocrystalline silicon cells, each $150 \mu \mathrm{m}$ thick and with an energy efficiency of $22 \%$. It uses lithium polymer batteries and was landed successfully by André Borschberg, CEO and co-founder of the Solar Impulse project, after a $26 \mathrm{~h}$ flight. Recent long-duration flight records for solarpowered planes operated by Solar Impulse and QinetiQ give cause for optimism in the field of solar aviation.

\section{Solar association formed}

A new association for engineers, managers and other professionals in the solar and related industries has been set up by a group of engineers in the USA. The main focus of the Solar Engineering \& Manufacturing Association (SEMA) will be education, technology, training and the advocacy of industrial standards.

"We set up SEMA because we believe there are very few resources available to technologists, engineers, managers and supervisors in the solar industry, both technically and professionally," says Matthew Holzmann, president of SEMA. "We want SEMA to be regarded as an indispensable resource for professionals around the world, including key stakeholders in research, manufacturing, academia and government."

SEMA will be a member-driven association, with individuals bringing their ideas to the group and sharing experiences. Potential priorities include developing the long-term reliability of solar cells, traceability, test strategies, the collation of standards, educational programmes and training.

"We hope to sponsor our first technical conference in the first quarter of 2011, where we will be focusing on manufacturing and engineering challenges and solutions," says Holzmann. "We are now inviting all stakeholders in the industry to participate and help establish SEMA as a member-driven professional organization."

For more information about SEMA, please visit www.solar-ema.org.

\section{NREL signs agreement with Solarmer}

The US Department of Energy's National Renewable Energy Laboratory (NREL) has signed a Cooperative Research and Development Agreement (CRADA) with Solarmer Energy to collaborate on improving the lifetime of plastic solar cells.

Under the terms of the CRADA, NREL researchers will evaluate the lifetime of Solarmer's high-performance active-layer systems. They will conduct the tests on NREL's combinatorial degradation system, which compares the performance of up to 360 organic photovoltaic devices in parallel under simulated solar conditions.

"We hope to improve plastic solarcell performance and extend cell lifetime through the development of stable device architectures and packaging systems," said NREL senior scientist Dana Olson, who is the principal investigator on the CRADA.

The project will cover the true lifetimes of materials and devices, a comparison of the materials and an examination of degradation mechanisms. Both parties are confident that they will also find better encapsulation and packaging approaches, which will contribute to improving the lifetime of plastic solar cells. 